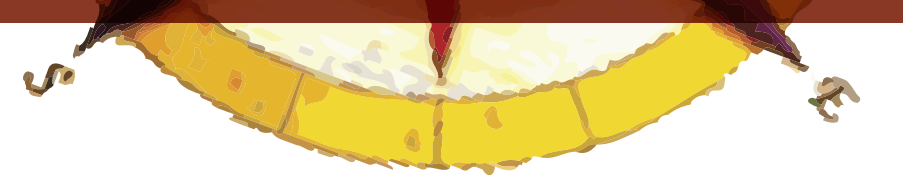

\title{
TENDÊNCIAS DA GEOGRAFIA: UM ESTUDO SOBRE AS CONCEPÇÕES DA REVISTA NOVA ESCOLA
}

\author{
Jerusa Vilhena de Moraes $^{1}$
}

Nathânia Nogueira de Paula²

\section{RESUMO}

A pesquisa tratata neste artigo é base de um projeto em construção, voltado para elaboração e discussão de novas propostas didáticas para o ensino de Geografia. Nosso objetivo para a primeira etapa do trabalho era analisar as metodologias para o ensino de Geografia, a partir do estudo das tendências investigativas de propostas didáticas presentes na Revista Nova Escola. Trata-se de uma revista mensal, de grande circulação no território brasileiro, presente nas escolas públicas desde o ano de 2000 e que aborda temas ligados à educação. Selecionamos artigos e reportagens que tratavam direta ou indiretamente sobre o ensino de Geografia nos períodos de janeiro de 2000 a dezembro de 2011. Encontramos uma tendência muito frequente: as reportagens com foco de Geografia Física e Geografia Humana. Também tivemos baixa frequência da Geografia unicamente Humana, da relação desta ciência com outras disciplinas a partir de diferentes temas, ou seja, com enfoque interdisciplinar.

Palavras Chave: Ensino e aprendizagem de geografia, propostas didáticas para geografia, revista nova escola e ensino de geografia.

\section{RESUMEN}

La investigación tratada en este artículo es base de un proyecto en construcción que trata sobre la elaboración y discusión de nuevas propuestas didácticas para la enseñanza de la Geografía. Nuestro objetivo para la primera etapa del trabajo era analizar las metodologías para la enseñanza de la Geografía, a partir del estudio de las tendencias investigativas de propuestas didácticas presentes en Revista Nueva Escuela. Se trata de una revista mensual, de gran circulación en el territorio brasilero, presente en las escuelas públicas desde el año 2000 y que aborda temas ligados a la educación. Seleccionamos artículos y reportajes que trataban directa o indirectamente sobre la enseñanza de Geografía entre el periodo de enero de 2000 a diciembre de 2011. Encontramos una tendencia muy

\footnotetext{
1 Professora adjunta na Universidade Federal Rural do Rio de Janeiro. Instituto de Educação- Departamento de Teoria e Planejamento do Ensino.

2 Estudante do $5^{\circ}$ período do Curso de Licenciatura Plena em Pedagogia da Universidade Federal Rural do Rio de Janeiro. Instituto de Educação. Bolsista PROIC.
} 
frecuente: reportajes con el foco de Geografía Física y Geografía Humana. También casi no encontramos el tratamiento de Geografía únicamente Humana y de relación de esta ciencia con otras disciplinas a partir de diferentes temas, o sea, con enfoque interdisciplinar.

Palabras Clave: Enseñanza y aprendizaje de geografía, propuestas didácticas para geografía, revista nueva escuela y enseñanza de geografía.

\begin{abstract}
Research discussed in article is based on a project in construction that deals about the development and discussion of new educational proposals for teaching of Geography. Our goal for the first phase of study was analyze methodologies for teaching geography from trends on educational proposals present at Revista Nueva Escuela. This journal has a wide circulation monthly on Brazil, present in public schools since 2000 and addresses educational issues. We selected articles and reports dealing directly or indirectly on teaching of geography between January 2000 to December 2011 period. We found a very common trend: articles with Physical and Human Geography focus. We nearly don't find articles with only Human Geography topics or articles about relationship between geography with other disciplines, ergo with interdisciplinary approach.
\end{abstract}

Keywords: Teaching and learning geography, Didactic approaches in geography, Revista Nueva Escuela, Geography teaching.

\title{
INTRODUÇÃO
}

A partir de algumas leituras que se baseiam em experiências no campo da metodologia, que são reais e muito próximas do cotidiano dos professores, verificamos que algumas ações podem ser tomadas para tornar a aprendizagem muito mais estimulante, e o ensino, coerente com a proposta de ajudar na formação de indivíduos que contribuam com a sociedade, questionando valores, levantando hipóteses sobre o que lhes acontece e argumentando cientificamente. Em se tratando da Geografia, é papel do professor explicar e contextualizar questões relacionadas ao meio ambiente, economia, política e cultura, apenas para citar alguns exemplos. Em se tratando da Geografia escolar, todas essas questões adquirem um peso enorme, pois então os professores tornam-se um elo entre o pensamento científico, o cotidiano e o pensamento escolar ${ }^{1}$.

A primeira parte do projeto de iniciação científica consistiu em investigar e analisar as propostas já produzidas (como as sequências didáticas sugeridas nas matérias da Revista Nova Escola) apresentadas como possíveis caminhos a serem percorridos na área de produção do conhecimento científico escolar e avaliar sua contribuição na melhoria da prática pedagógica (no que diz respeito aos professores) e da aprendizagem de conceitos científicos (no que diz respeito a professores e alunos) ligados à Geografia. Assim, o objetivo específico deste trabalho foi analisar a potencialidade dos modelos explicativos presentes nos materiais didáticos por meio da verificação da construção de argumentos científicos. 
A escolha da revista Nova Escola se deu por sua abrangência nacional, fácil acessibilidade no meio escolar e uso efetivo pelos professores na leitura e embasamento teórico e prático das aulas. A revista possui uma parceria com o Ministério da Educação, que permite que os exemplares cheguem às escolas públicas com mais de 50 alunos. Desde outubro de 2001 a revista passou a estar em todas as escolas públicas brasileiras, ou seja, também nas instituições com menos de 50 estudantes.

\section{METODOLOGÍA}

Para a pesquisa foram selecionadas reportagens da revista Nova Escola com conteúdos direcionados direta e indiretamente ao ensino de Geografia. O material selecionado está compreendido entre janeiro de 2000 a dezembro de 2011. As matérias escolhidas foram selecionadas com base em seus conteúdos, portanto também foram analisadas as reportagens que a revista não indicava que seus conteúdos pertenciam ao ensino de Geografia, mas que podiam ser trabalhadas devido aos conteúdos estarem com ela relacionados direta ou indiretamente.

Nos artigos analisados, foram encontrados alguns que não se encaixavam nos enfoques adotados para a pesquisa (preponderantemente Geografia Física, Humana ou com ambos enfoques). Foi entendido que em alguns destes a concepção teórica adotada pela revista entendia os temas como pertencentes aos vários campos de conhecimento; outros, a apenas um, mas que foi possível verificar a aplicabilidade ao ensino da Geografia.

Os casos anteriormente apresentados foram classificados nos enfoques a seguir:

- Ciências: com matérias que versavam sobre astronomia, estrutura e formação do planeta Terra;

- Historia e Língua Portuguesa correlacionadas com Geografia;

- Interdisciplinaridade (temas globais avulsos, sem indicação de matéria específica ou com sugestões para muitas matérias);

- Meio Ambiente: com matérias que versavam sobre fenômenos naturais, preservação, interação e impacto do homem na natureza.

Por conta das matérias encontradas, optamos por agrupá-las a partir de dois grupos:

- Natureza da Geografia tratada na matéria. Relaciona-se à concepção teórica da ciência geográfica por parte do autor da reportagem ou da Revista. Neste sentido são de três tipos: Humana, Física e Humana e Física;

- Conhecimentos e propostas de atividades que poderiam ser trabalhadas na Geografia. Algumas destas reportagens apresentavam de forma explícita a área de conhecimento da Geografia, como uma sugestão de uma atividade que poderia ser trabalhada em sala de aula pelo professor. Em outras, a matéria não dizia respeito à Geografia, mas era possível estabelecer uma correlação. 
Foram analisadas aproximadamente 110 Revistas Nova Escola. Aproximadamente, pois a revista também contém um encarte especial em seu interior disponibilizado pelo Unibanco e um caderno especial de planejamento também em seu interior, perfazendo um total de 130 . Sessenta dessas revistas encontram-se disponíveis on-line no próprio site da revista. $\mathrm{O}$ acesso às outras 70 revistas foi feito a partir da biblioteca da UERJ (Universidade do Estado do Rio de Janeiro). Das 130 revistas, houve um total de 136 reportagens selecionadas, com 88 matérias que apresentam conteúdos explícitos para Geografia e 48 com conteúdos que podem ser relacionados a ela, mas que a revista não elucida essa possibilidade. Nem todas as revistas continham conteúdos de Geografia e algumas revistas apresentaram mais de um conteúdo geográfico. Todo o material foi fichado.

De maneira geral, cabe ressaltar que muitas reportagens realizadas a partir de 2006 não apresentavam a dicotomia entre Geografia Humana e Física. Acreditamos que isso se deva ao fato do crescimento, no campo acadêmico e escolar, de discussões acerca do tema. Isso não significa que as reportagens eram entrelaçadas com embasamento conceitual do que se referia como aspectos do meio físico e social, e sim que, de maneira geral, apresentavam ambos enfoques no discurso presente, enfatizando que poderiam ser trabalhados os enfoques da geografia física e humana porém, sem sugestão que concretizasse essa relação. Isso reforça nosso entendimento de que a aparente dualidade (Geografia Física e Humana) é uma das características da ciência geográfica e que muito tem que ser discutido para que haja de fato um trabalho conjunto e uma compreensão de que meio físico e social, do ponto de vista da ciência geográfica, devem caminhar juntos.

Neste sentido, de maneira geral, foi considerado que a Geografia Humana e a Geografia Física estão fortemente relacionadas nos títulos das matérias e na apresentação inicial das reportagens, uma vez que as características naturais influenciam as humanas e vice-versa. Portanto, a fusão desses dois enfoques corresponde à análise da organização do espaço geográfico, que é o principal objeto de estudo da Geografia (Valcárcel, 2000).

Obviamente não foi ignorado o peso e a preponderância de um enfoque sobre outro no espaço geográfico. É necessário que o aluno aprenda conceitos de meio físico, como por exemplo, as formas de relevo e feições da terra, os processos que auxiliam na erosão do solo, a associação entre rede hidrográfica e formas de relevo. Apenas foi ressaltado que ignorar a inter-relação é promover a construção de um aprendizado estanque, em que uma área não dialoga com a outra, em que os elementos humanos não sofrem interferência do meio que ocupam e vice- versa. A aparente dicotomia é considerada como um grande ganho e ignorá-la é reforçar concepções de conhecimento que entendem que ora o aluno deve ter uma compreensão do que se chama agentes da natureza e, mais tarde, a compreensão de como vivem, por exemplo, os habitantes de determinada localidade.

\section{TENDÊNCIAS}

Com um quadro geral dos dados analisados, ou seja, todo o material selecionado a partir da Revista Nova Escola com conteúdos de Geografia ou relacionados a ela, foi possível fazer muitas observações e obter uma gama de informações importantes. É preterido expor e apresentar exemplos a fim de elucidar os conteúdos e características que as reportagens apresentam que foram considerados importantes e cruciais para o entendimento e percepção das tendências.

Para o período analisado, há uma ênfase nas matérias relacionadas aos conteúdos e conceitos da Geografia Física, como pode ser verificada nesse período de 11 anos. As reportagens apresentam 
informações interessantes no sentido de propiciar atividades em sala que poderiam levar a uma maior participação dos alunos. São trabalhados, neste enfoque, conceitos como de localização, espaço, território, para o reconhecimento e conhecimento do espaço em que os alunos vivem. Tais reportagens variam em todas as séries de ensino, porém constatamos que a Educação Infantil e as séries iniciais não são, de maneira geral, priorizadas nas matérias.

O gráfico a seguir evidencia a incidência com que os enfoques acerca da Geografia são tratados pela revista. O gráfico não contabiliza as reportagens que também podem ser trabalhadas em Geografia, mas que a revista as classifica como sendo de outras áreas. O gráfico só contabiliza as reportagens que a Revista Nova Escola classifica seu conteúdo como de Geografia.

\section{TENDÊNCIAS INVESTIGATIVAS ANALISADAS}

(ANOS 2000 A 2011)

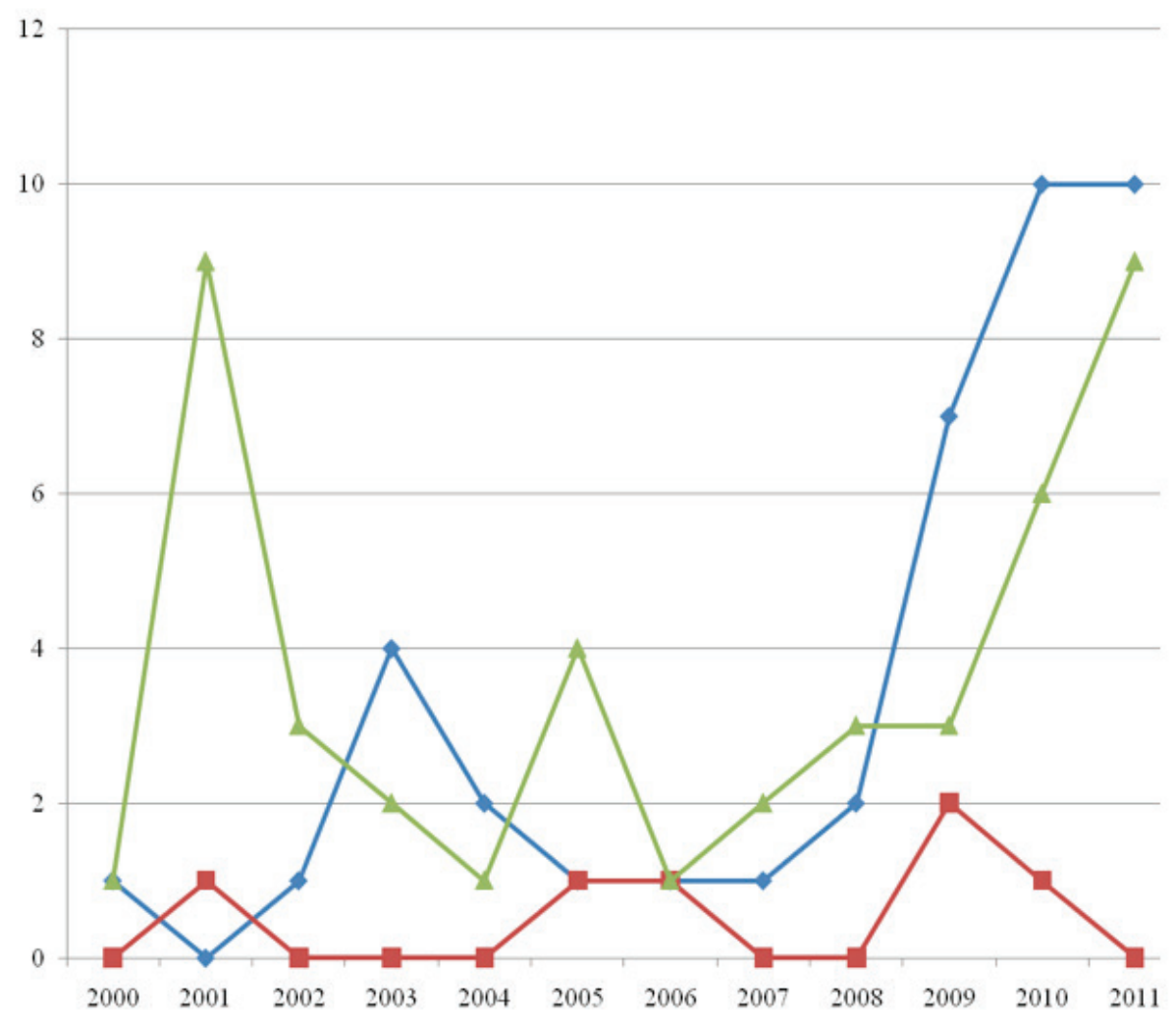

$\multimap$ Geografia Fisica $\quad-$ Geoografia Humana $\quad-$ Geografia Fisica e Humana

Gráfico 1: Tendências Investigativas Analisadas (Anos 2000 a 2011). Nathânia Nogueira de Paula. Relatório de iniciação cientifica (PROIC, UFRRJ, 2012).

Pode-se observar no gráfico a seguir, a incidência das reportagens que não são denominadas pela Revista Nova Escola como sendo de conteúdos para serem trabalhados em Geografia, mas que podem ter uma sequência didática com esta ciência. Esta pode ser relacionada com muitas áreas, como mostra o gráfico abaixo: 


\section{TEMAS QUE TAMBÉM PODEM SER TRABALHADOS EM GEOGRAFIA}

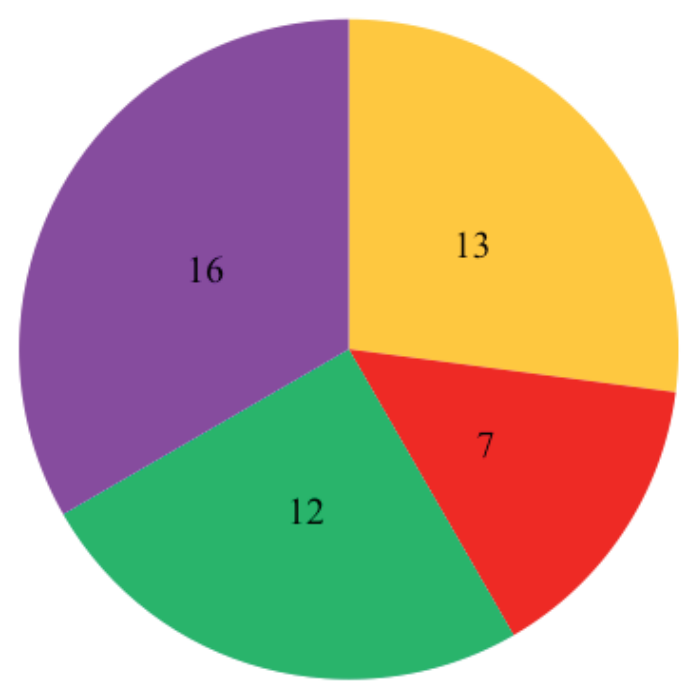

Área del gráfico
Ciências: astronomia, composição e formação da Terra;

- Historia e/ou Língua Portuguesa correlacionadas com Geografia;

- Interdisciplinalidade (temas globais avulsos, sem indicação de matéria específica);

- Meio Ambiente: Preservação, interação e impacto do homem, fenômenos naturais.

Gráfico 2: Temas que também podem ser trabalhados em Geografia. Nathânia Nogueira de Paula. Relatório de iniciação científica (PROIC, UFRRJ, 2012).

Verificamos que alguns conceitos apresentados pela Geografia escolar como necessários para uma educação geográfica (como paisagem, região, natureza, sociedade, território e lugar, tal como Cavalcanti, 1998, propõe) são pouco discutidos. Assim, a aprendizagem conceitual e mesmo as propostas ligadas à melhoria da educação correm o risco de tornarem-se significantes vazios, tal como ressalta Lopes (2008).

Entendemos significantes vazios como ações decorrentes de palavras de significados vazios, podendo ser o entendimento superficial das questões relacionadas ao uso que se faz dos conceitos geográficos, à incapacidade de resolver problemas associados a esses conceitos e também as práticas docentes decorrente desse entendimento.

Comparando com matérias designadas como de Geografia, é possível observar que o número de conteúdos não designados a esta, embora não sendo maior, é grande e muitas são suas vertentes.

Em um gráfico geral tem-se uma visão melhor do que a revista apresenta nesse período de 11 anos:

A partir do gráfico é possível inferir a carência de matérias designadas como Geografia Humana, e a quantidade considerável de conteúdos Físico-Humanos. O entendimento e análise da organização do espaço geográfico necessitam das duas áreas, portanto, não é um fato estranho a frequência desses conteúdos juntos. A própria revista não separa os temas, simplesmente os designa como 


\section{GRÁFICO GERAL DE CONTEÚDOS}

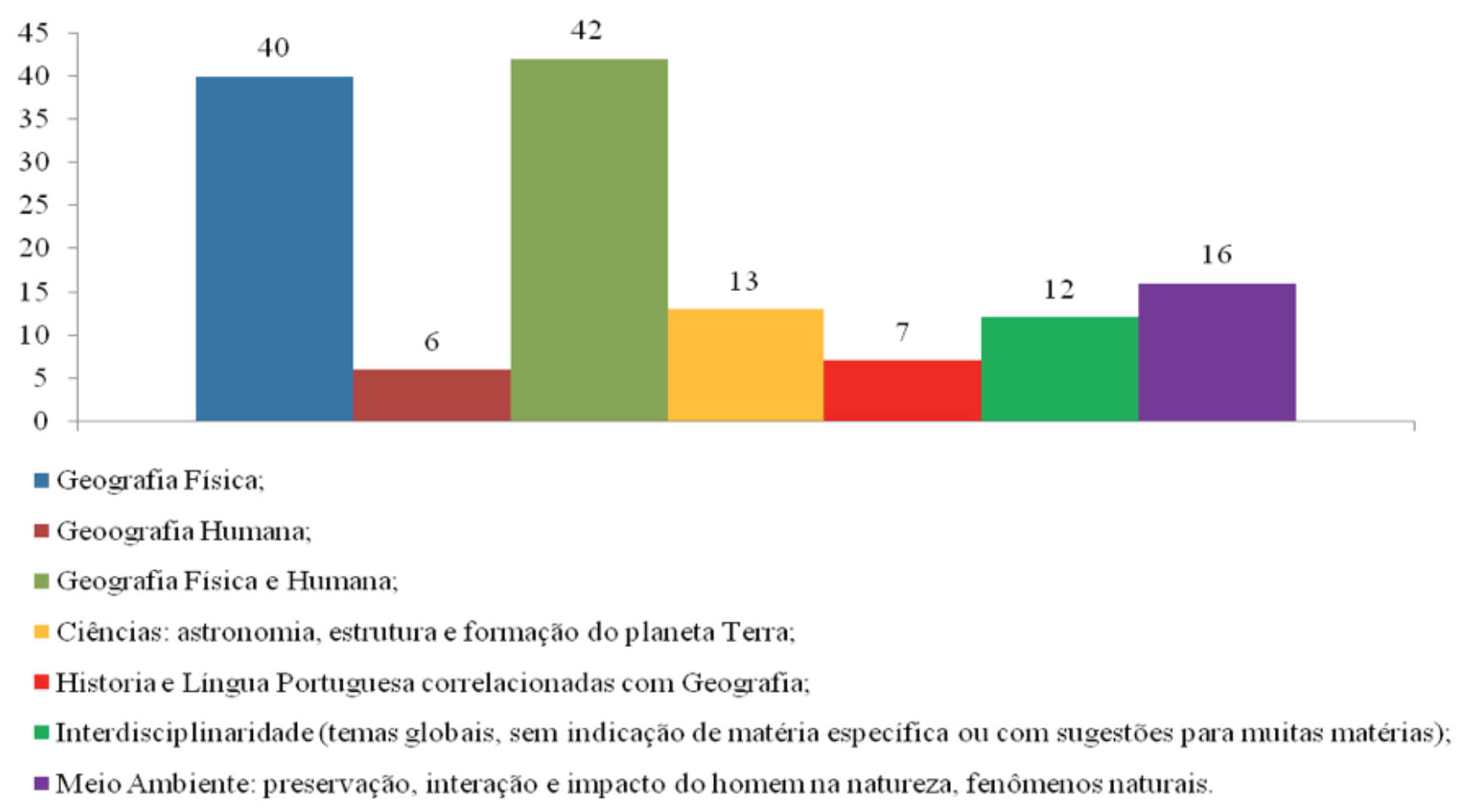

Gráfico 3: Grafico geral de conteúdos Revista Nova Escola. Nathània Nogueira de Paula. Relatorio de iniciação científica (PROIC, UFRRJ, 2012).

Geografia e, de maneira geral, apresenta propostas vinculadas aos conteúdos de Geografia Humana e Física. O reconhecimento da não desvinculação do meio físico ao social é crucial para a melhor compreensão entre a sociedade e o meio.

Nessa sessão temos estudos demográficos realizados com alunos, projetos, alguns destes contemplados pelo Prêmio Victor Civita (muitas são as experiências relatadas aqui). Observa-se uma preocupação dos educadores em trazer os conteúdos de forma que ao final do projeto o entendimento seja por inteiro.

Os conteúdos das matérias muitas vezes são relatados das seguintes formas:

- Relato de experiência de professores em contextos locais distintos, ou seja, com a apresentação de experiências em escolas da periferia, carentes, escolas de ponta e escolas mais equipadas e com maior recurso;

- Relato de experiência de professores em contextos locais distintos, mas cujo enfoque da matéria é o conteúdo do que trabalham no que se configura como educação formal e não formal em seus múltiplos contextos. Assim, são relatadas experiências de professores que utilizaram proposta de trabalho de campo, entrevistas, organizações diferenciadas do espaço da sala de aula, etc.;

- Proposta de sequência didática, apresentada como um plano de aula para se trabalhar os 
conteúdos. Às vezes a sequência didática é proposta por uma consultora, às vezes pelo professor apresentado na reportagem. Na grande maioria dos casos, as sequências didáticas são destinadas a alunos do $6^{\circ}$ ao $9^{\circ}$ ano.

Pode haver também pequenas matérias que são respostas a perguntas de leitores da revista, enviados por carta ou e-mail. Porém esse tipo de conteúdo só é encontrado a partir de 2008 e $100 \%$ dele pode ser entendido como pertencente ao enfoque da Geografia Física.

As atividades realizadas nas matérias propiciam um ambiente investigador para os alunos, porém muitas vezes essas situações propostas só podem ser trabalhadas em um ambiente especifico e, a grande maioria das reportagens são pouco aprofundadas nos aspectos da ciência geográfica e mesmo pedagógica.

A seguir apresentam-se alguns artigos. Poderá ser observado seu enfoque e proposta, ou seja, como os conteúdos são trabalhados. Será possível observar as atividades e como essas se desenvolvem em seus espaços específicos e as propostas didáticas.

No exemplo a seguir temos um conteúdo indicado para as séries iniciais e 2 propostas didáticas.

\section{Território do saber. Como abordar conteúdos de cartografia do $1^{\circ}$ ao $5^{\circ}$ ano.}

Publicado em: Revista Nova Escola. Edição: 214. Agosto de 2008, por: Ana Rita Martins.

Natureza da Geografia: Física;

Palavras chave: Cartografia, localização, clima e vegetação, séries iniciais

"Para ajudá-lo a utilizar o mapa político disponível nesta página, NOVA ESCOLA preparou planos de aula para as séries iniciais do Ensino Fundamental (no quadro ao lado). No $1^{\circ}$ e no $2^{\circ}$ anos, as crianças começam a descentralizar seu ponto de vista - ou seja, tornam-se capazes de enxergar a posição de um objeto em comparação a outro, e não somente em relação a si mesmas. O trabalho cartográfico pode começar por um ambiente conhecido, como a escola. Desenhando a sala de aula, os alunos aprendem conceitos como lateralidade, proporcionalidade e distância. Com esse conhecimento, é possível usar o mapa do Brasil para reforçar as noções de perto e longe, além de interpretar seus principais símbolos. Já familiarizados com outras representações geográficas, alunos do $3^{\circ}$ ao $5^{\circ}$ ano entendem conceitos mais específicos, como o de limite espacial, assim como a noção de escala."

Esse conteúdo é quase que único, pois ele apresenta uma proposta de introdução à cartografia, que trona-se frequente na revista a partir do ano 2006, com a diferença de que esta matéria traz sugestões de atividades para as séries iniciais. Os outros conteúdos de introdução à cartografia são indicados em maior parte a partir do $6^{\circ}$ ano, ou seja, o aluno só teria contato com esse conteúdo no Ensino Fundamental II. A seguir segue duas das 3 propostas didáticas indicadas pela revista para $o$ trabalho do conteúdo. Além das propostas didáticas a matéria é acompanhada por um mapa, que contem as informações necessárias para as atividades. Propostas didáticas sugeridas pela Revista Nova Escola: 


\section{PERTO E LONGE}

Objetivos: Discutir a importância do mapa e suas informações; Trabalhar as noções de perto e longe; Estimar distâncias entre a cidade em que se vive e outros pontos.

Conteúdos: Leitura e decodificação de símbolos cartográficos; Identificação de topônimos (nomes próprios de lugares).

Anos: $1^{\circ}$ e $2^{\circ}$.

Tempo estimado: 3 aulas.

Material necessário: Lápis preto e de cor, borracha e papel.

\section{Desenvolvimento}

$1^{\text {a }}$ ETAPA: Pergunte aos alunos se conhecem o mapa do Brasil e fale sobre a utilidade dele. Peça que cada estudante desenhe o próprio mapa do país.

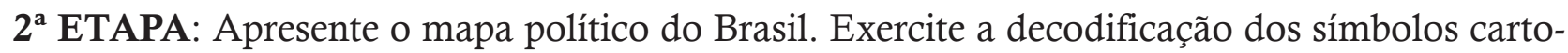
gráficos (letras maiúsculas para estados, letras de diferentes tamanhos conforme a população da cidade). Ajude-os a localizar onde vivem.

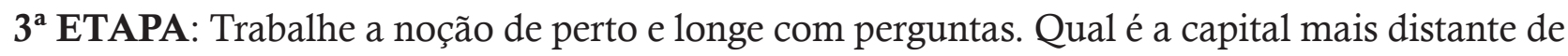
onde estamos? E a mais próxima? Estamos longe do litoral?

$4^{a}$ ETAPA: Peça que os estudantes comparem seus desenhos iniciais com o mapa político. Fale sobre o nome oficial do mapa e explique que ele revela as informações básicas que um cidadão precisa saber para se localizar e se deslocar pelo país.

Avaliação: Avalie o envolvimento e a produção dos alunos no desenho inicial e nos debates. Exatidão nas respostas não é fundamental, mas sim a criação de raciocínios espaciais.

Consultoria: Julia Pinheiro Andrade Professora e formadora nas áreas de Geografia e Iniciação à Pesquisa da Escola Castanheiras, em São Paulo.

\section{LIMITES ESPACIAIS}

Objetivos: Conhecer e identificar as principais formas de delimitação espacial num mapa.

Conteúdos: Limites espaciais; Estados e regiões do país.

Anos: $3^{\circ}$ ao $5^{\circ}$.

Tempo estimado: Três aulas.

Material necessário: Lápis preto e de cor, borracha e papel. 


\section{Desenvolvimento}

$1^{\text {a }}$ ETAPA: Comece perguntando que limites espaciais os alunos conhecem na escola: a carteira, a sala de aula, o prédio etc. Mostre que eles delimitam a responsabilidade de cada um sobre o espaço (alunos, no caso das carteiras, professores, no caso das salas de aula, direção, no caso do prédio), ressaltando que o mesmo ocorre com os limites de municípios, estados e nações (subordinados a prefeitos, governadores e presidentes).

$2^{\text {a }}$ ETAPA: Pergunte aos alunos o que eles imaginam ser um limite entre duas regiões. Peça que produzam um desenho representando o Brasil e as divisões adequadas para governá-lo bem. Deixe as crianças livres para expor suas representações mentais.

$3^{\text {a }}$ ETAPA: Apresente o mapa político regional. Discuta a seguinte questão: por que o Brasil é dividido em estados? Por que eles são agrupados em grandes regiões? Cubra as legendas e peça que as refaçam. Incentive-os também a comparar seus mapas com o oficial.

Avaliação: Verifique o envolvimento e a participação dos alunos no desenho inicial, na construção das legendas e nos debates. Além de raciocínio espacial, o ideal é que consigam desenvolver argumentos sobre a função e a pertinência dos limites espaciais.

Consultoria: Julia Pinheiro Andrade Professora e formadora nas áreas de Geografia e Iniciação à Pesquisa da Escola Castanheiras, em São Paulo.

É possível observar que ambos os conteúdos são complementares, a proposta de $3^{\circ}$ ao $5^{\circ}$ ano é mais elaborada que a do $1^{\circ}$ ao $2^{\circ}$, porém elas se completam. Os conteúdos nas séries iniciais precisam ser bem trabalhados, pois estes são acumulativos para as séries seguintes, com elementos bem trabalhados no $1^{\circ}$ e $2^{\circ}$ ano o aluno chega ao $3^{\circ}$ ano com compreensão suficiente para tarefas mais elaboradas, são conhecimentos para a vida toda.

Agora temos outra reportagem, também com conteúdos de cartografia, porém direcionada ao Ensino Fundamental II:

2. Ensinando a ler mapas e paisagens. A cartografia deve estar sempre presente nos planos de aula porque é uma ferramenta útil para o aluno compreender a realidade.

Publicado em: Revista Nova Escola, Caderno de Planejamento. Edição 148. Dezembro de 2001, por Paola Gentille.

Natureza da Geografia: Física;

Palavras chave: mapas, alfabetização cartográfica, Ensino Fundamental II.

"O principal objetivo do professor de Geografia de $5^{\mathrm{a}}$ a $8^{\mathrm{a}}$ série é fazer com que o aluno analise paisagens, represente graficamente o que observou, estabeleça comparações com outras realidades e reflita sobre suas constatações, à luz da teoria e da prática. "É um tipo de iniciação alfabética, só que em outra linguagem", ilustra Diamantino Pereira, coordenador do curso de Geografia da Pontifícia Universidade Católica de São Paulo. Partindo sempre de uma realidade mais próxima do aluno, é possível estabelecer uma seqüência didática e propor atividades que permitam a construção de con- 
figurações territoriais sobrepostas e inter-relacionadas. Walter Luiz Macedo, professor da $7^{\text {a }}$ série do Colégio Santa Maria, em São Paulo, reserva o primeiro bimestre para retomar os conteúdos já vistos, sempre com uma nova abordagem e diferente nível de aprofundamento. Para isso, ele se reúne com o colega responsável pela disciplina no ano anterior ou lê seus registros. Uma das primeiras atividades propostas por ele que se repete ao longo do ano é a produção e leitura de mapas. Os grupos estudam o bairro em relação à cidade e à região, o Estado no contexto do país, a nação comparada com outras e como fatos políticos, econômicos e sociais do resto do mundo influenciam o nosso continente. O espaço reservado para Geografia no Santa Maria é de dois encontros por semana, um deles com horário dobrado. Macedo reserva o tempo maior para trabalhos mais demorados, como colocação de legendas, pesquisas externas ou observação e registro de paisagens. As aulas simples são usadas para diálogos e troca de informações, geralmente para introduzir ou concluir um tema. (...).

\section{Preparando saídas}

Os estudos do meio devem ser sempre muito bem planejados. No terceiro bimestre deste ano, para conhecer melhor a geopolítica do nosso continente, Macedo programou uma visita ao Memorial da América Latina, na capital paulista. Isso exigiu dele três tardes de preparação: a primeira para conhecer o complexo cultural e traçar o roteiro de visita e a segunda para detalhar os temas que poderiam ser explorados pelos grupos e planejar atividades intermediárias, como leitura da paisagem do trajeto da escola até o local. Por fim, ele levantou na biblioteca e na videoteca do Memorial alguns títulos que poderiam complementar as pesquisas. "A visita durou uma manhã, mas o preparo e as atividades posteriores, como análise e produção de textos e discussão de conceitos, ocuparam todas as outras aulas do bimestre", relata Macedo. De volta à classe, os alunos ouviram o CD de um grupo musical que toca punk e ska (ritmo jamaicano). Pelos instrumentos utilizados, eles deduziram as influências culturais na formação dos povos latino-americanos.

Mesmo com todas as atividades programadas, imprevistos de todo tipo podem mudar os rumos. $\mathrm{Na}$ opinião de Diamantino Pereira, o planejamento inicial deve ser rigoroso quanto às finalidades do ensino, mas flexível quando se trata dos conteúdos: "Quando temos como carro-chefe os objetivos, não importa os temas que serão usados para atingi-los".

\section{Tempo para reforço}

Renata Del Mônaco procura "prever os imprevistos" na elaboração de seus planos de aula. Ela leciona nas escolas Projeto Vida e Cooperativa, ambas de São Paulo. "Deixo livre pelo menos uma aula por mês, justamente para encaixar debates sobre atualidades, reforçar conteúdos que não foram apreendidos ou fazer algum passeio não planejado."

Com quinze anos de magistério, ela conseguiu formar um bom arquivo pessoal de imagens, com panfletos e recortes de jornais e revistas. Duas atividades permanentes desenvolvidas a partir da $6^{\mathrm{a}}$ série a ajudam nessa tarefa: o mural com curiosidades geográficas e o painel temático. Os alunos são incentivados a buscar informações sobre temas, pré-definidos ou não. No final do ano, todo o material é arquivado numa pasta, que servirá às turmas seguintes como fonte de consulta. Renata acredita ser fundamental ao professor de Geografia ler diariamente jornais e revistas e ter sempre em mãos uma agenda de bolso. "Lendo ou observando as pessoas e a paisagem, onde quer que estejamos, podemos ter ótimas idéias para trabalhar em sala de aula". Segurando um bloquinho e uma caneta, ela percorre todos os dias, de metrô, o trajeto de casa até as escolas em que trabalha. Foi no vagão, observando o mapa colocado junto a todas as portas, que ela teve a idéia de propor uma atividade em duplas: cada aluno deveria ensinar ao colega, com texto e mapa, o caminho da escola até sua casa. Essa foi a atividade que introduziu o estudo da cartografia na $6^{a}$ série."

Muitas matérias com conteúdos de Geografia Física são encontradas, com números expressivos de mapas, construção de mapas, mapeamentos, escalas e um forte contato e busca do reconheci- 
mento do meio que cerca o educando. São experiências de professores na introdução e desenvolvimento da cartografia, ou seja, a alfabetização geográfica e como esta deve ser iniciada a partir do reconhecimento do meio em que a criança está inserida. Sobre esta questão, Cavalcanti (1998) amplia esta ideia ao afirmar que: "(...) o ensino de Geografia tem a função de lidar com a espacialidade e com o conhecimento geográfico de cada um para provocar neles alterações no sentido de uma ampliação. Isso é possível pela reflexão e pelo exercício da abstração propiciado com o tratamento de conhecimentos científicos" (Cavalcanti, 1998. p. 135).

As experiências na reportagem são apresentadas, de início, como uma proposta que sai de uma descrição e reconhecimento do bairro onde a criança mora, o trajeto que ela faz até chegar a escola, e, depois, a história do lugar, como ele se formou. É uma (re) construção gradativa e conjunta de alunos e professores até interação total do macro, o estado, o país as relações com os outros países, até a formação e constituição da terra. Em termos conceituais, a reportagem obedece a classificação do local para o global, sem apresentar a possibilidade do caminho inverso (Straforini, 2008).

É na iniciação ao reconhecimento dos elementos do mapa e como este se constitui que os estudantes têm a possibilidade de conhecer os elementos utilizados para descrever o meio que os cercam. Ou seja, esse tipo de trabalho permite que a criança leia o meio a sua volta, reforçando a ideia trabalhada por Castellar \& Moraes (2010, p. 23): "Ensinar a ler em Geografia significa criar condições para que a criança leia o espaço vivido, utilizando a cartografia como linguagem para que haja o letramento geográfico."

A alfabetização geográfica implica em um trabalho com os conhecimentos ligados ao uso de mapas (como a orientação e localização) e fatores que estão relacionados à compreensão do conceito científico, como aspectos da cultura, economia e política.

A preocupação por criar condições para que o processo de letramento geográfico se efetive a partir das noções cartográficas estimula o raciocínio espacial do aluno. A cartografia passa a ter um novo valor, ela torna-se um meio de comunicação e linguagem possibilitando aos alunos maior compreensão dos conceitos passados e dos que serão apresentados. Mas para que tudo isso aconteça é preciso dar condições para a criança no processo de ensino e aprendizagem. As matérias são bem claras quanto a isso, a importância do reconhecimento do espaço em que o aluno está inserido, da valorização aos conhecimentos que os alunos trazem para dentro de sala, exaltação da cultura e história local. Por muitas vezes um conteúdo começa como Geografia Física e termina como Geografia Física e Humana, por englobarem todos os elementos (físicos, sócio-culturais, políticos, etc.).

Teremos maior compreensão disso com o próximo exemplo, que trata de geopolítica e seu desdobramento no mundo atual.

3. As relações internacionais e os organismos multilaterais. Em cena, as instituições que regulam as relações entre os Estados nacionais em diferentes níveis e esferas, como a economia e a geopolítica.

Publicado em: Revista Nova Escola. Edição 228. Dezembro de 2009, com o título Conexão Mundial, por: Léia Tavares.

Natureza da Geografia: Física e Humana; 
Palavras chave: Relações internacionais, geopolítica e organismos multilaterais, Ensino Fundamental II.

"O estudo das ligações econômicas, políticas, culturais e sociais que existem entre os países e o movimento veloz do trânsito de capitais, mercadorias e informações fazem surgir a ideia de que as fronteiras entre os Estados não existem mais. Essa é uma excelente percepção para ser tomada como ponto de partida nas aulas sobre como se dão as relações internacionais.

Os alunos precisam tomar consciência de que existem instituições reguladoras das dinâmicas que envolvem dois ou mais Estados nacionais. "São os organismos multilaterais, espaços instituídos para regulamentar ações de naturezas diversas", explica Ricardo Seitenfus, doutor em Relações Internacionais e autor de livros sobre o assunto. A Organização das Nações Unidas (ONU) é o mais abrangente deles e reúne atualmente 192 países, além de órgãos que cuidam de assuntos específicos, como o Programa das Nações Unidas para o Desenvolvimento (Pnud). (...).

Na EE Professora Benedita Arruda, em Jundiaí, a 63 quilômetros de São Paulo, simulações de reuniões da Assembléia Geral e do Conselho de Segurança, as duas instâncias básicas da ONU, permitiram que os jovens do $9^{\circ}$ ano praticassem o que tinham estudado sobre as relações internacionais. Primeiro, a garotada apresentou um relatório sobre a fome na África e organizou um debate a respeito para levantar sugestões de estratégias que poderiam ser implementadas a fim de solucionar o problema. "Depois, foi a vez de um encontro do Conselho. Na pauta, a realização de testes nucleares pela Coréia do Norte. Um grupo representou os coreanos e o outro os conselheiros da ONU", diz o professor Elias Noronha. Para defender e reprovar a perigosa medida, a turma pesquisou bastante: o que a ONU defendia, os motivos que levaram a Coréia do Norte a descumprir o combinado e as possíveis penalidades que os países-membros poderiam sugerir (leia a sequência didática no quadro à direita).

Num percurso como esse, é importante orientar a garotada a observar que as decisões de um país a respeito de seus atos são soberanas - os organismos multilaterais estabelecem regras. Cumpri-las ou não (e arcar com as consequências) é uma decisão a ser tomada. A invasão do Afeganistão pelos Estados Unidos após os ataques às Torres Gêmeas, em Nova York, em 2001, é um exemplo desse impasse, já que a ONU, na época, não apoiou a atitude do governo norte-americano."

A proposta didática apresentada pela Revista Nova Escola é a que se segue:

\section{A ONU E O MUNDO}

Objetivo: Conhecer o contexto do surgimento da Organização das Nações Unidas (ONU) e qual é seu papel no mundo no âmbito das relações internacionais.

Conteúdos: Relações internacionais; Organismos multilaterais.

Anos: $8^{\circ}$ e $9^{\circ}$.

Tempo estimado: Quatro aulas.

Material necessário: Mapa mostrando a inclusão dos países na ONU entre 1945 e 2006, como o intitulado Ano de Admissão, do Atlas da Mundialização - Compreender o Espaço Mundial Contemporâneo (pág. 114, Ed. Saraiva) e computadores com acesso à internet. 


\section{Desenvolvimento}

$1^{a}$ etapa: Inicie uma conversa com os alunos perguntando quem eles acham que governa o mundo e se sabem o que quer dizer a expressão "relações internacionais". Com base no que for dito, direcione a atenção do grupo para o que pretende explorar - as relações entre os países nos âmbitos político, econômico e cultural, entre outros, e como elas são regulamentadas. Feito isso, questione a turma sobre o papel da ONU nesse contexto. Durante as falas dos estudantes, é importante desmistificar a ideia simplista de que ela seja somente uma organização que prega a paz mundial. Para isso, ao longo do bate-papo, pontue suas indagações com as ações da ONU que abordam questões de saúde e de cuidados com a infância, por exemplo, realizadas pela Organização Mundial da Saúde (OMS) e pelo Fundo das Nações Unidas para a Infância (Unicef), respectivamente.

$2^{\text {a }}$ etapa: Reúna a garotada em duplas ou trios e convide todos para ir ao laboratório de informática. É hora de pesquisar o tema na internet. Distribua os seguintes tópicos entre os grupos: criação da ONU e contexto histórico que marcou a época, objetivos da instituição, órgãos que a compõem, documentos criados por ela e ações atuais da organização. Instrua os alunos a explorar o site oficial, uma fonte confiável para a atividade. Oriente que tomem notas sobre os itens acima.

$3^{\text {a }}$ etapa: De volta à sala de aula, socialize o conhecimento levantado pelos grupos, com foco nas questões iniciais da proposta de trabalho.

$4^{\text {a }}$ etapa: Apresente aos alunos o mapa Ano de Admissão, do Atlas da Mundialização. Porém oculte o gráfico Cronologia das Admissóes, que aparece logo abaixo dele - para que a turma chegue sozinha a pelo menos algumas conclusões indicadas nele. Estimule uma análise a respeito dos países ingressantes na ONU a partir de 1946. Quais as características comuns a eles? Peça que, mais uma vez, todos tomem nota das observações que realizam ao longo da exploração.

Avaliação: Peça que os jovens elaborem uma dissertação a respeito do papel que a ONU desempenha hoje e o cenário que dominava o mundo na época em que foi criada. Avalie se eles pontuam a importância do organismo para estabelecer regras em diferentes esferas, mas que elas não ferem a soberania dos Estados nacionais.

Consultoria: Elias Noronha Professor da EE Professora Benedita Arruda, em Jundiaí; Roberto Giansanti Geógrafo, autor de livros didáticos e consultor educacional.

Os conteúdos geopolíticos carregam em sua natureza geográfica o físico e o humano, pois tratam de território e formação de espaço, e para a compreensão destes é preciso realmente articular conceitos (como, por exemplo, a ocupação do local e a observação do solo onde a população se fixou). Porém, esta concepção da necessidade da articulação entre ambos os enfoques (físico e humano) não é trabalhada na matéria.

Do ponto de vista do autor desta reportagem, conseguimos identificar os motivos associados à escolha da sequência que acabou adotando. Na matéria, fica evidente, assim, que o mundo é político, os órgãos multilaterais regularizam a política mundial, essas políticas estão carregadas com 
as características de cada país. Logo, esses órgãos são necessários, para tentar minimizar conflitos e a melhor e colaboração entre os países. É isso que a reportagem traz em sua sequência didática e exemplos na própria matéria.

Do ponto de vista da aprendizagem de conceitos geográficos, os alunos precisam ter esse contato, compreender as diversidades e necessidades da criação de instituições como, por exemplo, a Organização das Nações Unidas (ONU). É nesse cenário que a busca pela compreensão global pelo aluno pode começar, a partir, por exemplo, do reconhecimento de diversos cenários, culturas, políticas, entre outros.

Nota-se também que o trabalho proposto só funcionaria em um ambiente especifico, no caso uma escola com laboratório de informática. As adversidades que encontramos nas escolas públicas e também nas privadas, considerando a diversidade existente no território nacional e cujas escolas recebem a Revista Nova Escola mostram-nos uma realidade diferente da proposta. Um outro ponto refere-se a necessidade do professor entender que esta atividade não pode encerrar-se nela mesmao que também não foi deixado claro na reportagem- uma vez que a articulação entre conceitos da geografia física e humana ficou deficitária.

O que pode ser analisado nas matérias é que vários conteúdos são apresentados com propostas de trabalho interdisciplinares. O que é ressaltado nas matérias que foram lidas é que há a necessidade de conseguir compreender a integralidade do conteúdo, que o todo é dividido em partes. No caso das disciplinas escolares, cabe ao professor tentar trabalhar o conteúdo permitindo ao aluno o entendimento que essa parte pertence ao todo, e que os conteúdos em si se completam. No entanto, esta perspectiva de enfoque interdisciplinar é apresentada ao professor de uma forma ainda superficial, em que fica a impressão de que cada conteúdo pode ser trabalhado, mas que não são trabalhados com mais profundidade.

Um conteúdo muito presente e ao mesmo tempo apresentado de forma confusa com indução a aprendizagem errônea é o aquecimento global, sua relação com o Efeito Estufa e como estes interferem no nosso planeta. A seguir serão apresentadas duas perguntas realizadas por leitores, que explicitarão as confusões relacionadas a esse assunto.

\section{4. É verdade que o gelo dos pólos está derretendo em ritmo acelerado?}

Publicado em: Revista Nova Escola. Edição 242. Maio 2011, POR: EDUARDO LIMA, COM REPORTAGEM DE RITA TREVISAN.

CONSULTORIA DE JEFFERSON SIMÕES, PROFESSOR DO INSTITUTO DE GEOCIÊNCIAS DA UNIVERSIDADE FEDERAL DO RIO GRANDE DO SUL (UFRS). EM RESPOSTA A PERGUNTA FEITA POR: PEDRO LUÍS AMARANTE, VILA NOVA, ES.

\section{PALAVRAS CHAVE: DERRETIMENTO DOS PÓLOS, AQUECIMENTO GLOBAL.}

Aquecimento Global

É verdade que o gelo dos polos está derretendo em ritmo acelerado?

Eduardo Lima. Com reportagem de Rita Trevisan 
Pergunta enviada por Pedro Luís Amarante, Vila Nova, ES.

Por enquanto, isso é verdade apenas no Círculo Polar Ártico. Imagens de satélite revelam que, nos últimos 30 anos, o aquecimento global fez diminuir significativamente a cobertura de gelo dessa região. A expectativa da comunidade científica é que, já nas próximas décadas, os mares do norte fiquem totalmente livres de água congelada durante o verão - algo jamais registrado. No Círculo Polar Antártico, entretanto, o derretimento ainda é pontual, concentrado principalmente na península Antártica (aquela língua de terra cercada de ilhas que avança em direção à América do Sul). O problema é que, segundo os pesquisadores, o degelo vai se generalizar neste século. Tudo porque a temperatura do planeta não para de subir, empurrada pelos gases de efeito estufa lançados na atmosfera. Quanto maior for o derretimento, maior será a quantidade de radiação solar absorvida pelo oceano. Nesse cenário, a temperatura da água subiria, trazendo consequências catastróficas para a fauna marinha. Já para a humanidade, isso significaria a elevação do nível dos mares e o provável incremento na ocorrência de fenômenos climáticos extremos.

Consultoria: Jefferson Simões, professor do Instituto de Geociências da Universidade Federal do Rio Grande do Sul (UFRS).

Na sequência, outra matéria, com um questionamento relacionado ao Efeito Estufa. É possível observar a ligação que é feita entre aquecimento global e efeito estufa, como estes são trabalhados pela revista e por que esses temas distintos são tão relacionados a ponto de causar assim certa confusão, no momento de medar a formação de conceitos.

\section{O que é efeito estufa e quais são suas consequências?}

Publicado em: Revista Nova Escola. Edição 224, AGOSTO 2009, POR: BEATRIZ SANTOMAURO, COM REPORTAGEM DE RITA TREVISAN E CONSULTORIA DE LUCIANO MARANI, DOUTOR EM GEOFÍSICA ESPACIAL E PESQUISADOR DO INSTITUTO NACIONAL DE PESQUISAS ESPACIAIS (INPE). EM RESPOSTA A PERGUNTA FEITA POR: HELIANA DIAS OLIVEIRA, NÚCLEO BANDEIRANTE, DF.

\section{PALAVRAS CHAVE: AQUECIMENTO TERRESTRE, EFEITO ESTUFA.}

\section{GEOGRAFIA}

O que é efeito estufa e quais são suas consequências?

Beatriz Santomauro. Com reportagem de Rita Trevisan

\section{Pergunta enviada por Heliana Dias Oliveira, Núcleo Bandeirante, DF.}

\section{Ilustração: Luis Iria}

O efeito estufa é um fenômeno causado por gases (principalmente gás carbônico, clorofluorcarboneto, metano e óxido nitroso) que estão presentes na atmosfera desde a formação da Terra, há cerca de 4 bilhões de anos. São eles os responsáveis por absorver a radiação infravermelha vinda da Terra e permitir que a temperatura na superfície fique na média de $15^{\circ} \mathrm{C}$ (veja o infográfico ao lado). Sem esses gases, a vida só seria viável para micróbios em regiões aquecidas por fontes geotermais. Consultoria Luciano Marani, doutor em Geofísica Espacial e pesquisador do Instituto Nacional de Pesquisas Espaciais (Inpe). 


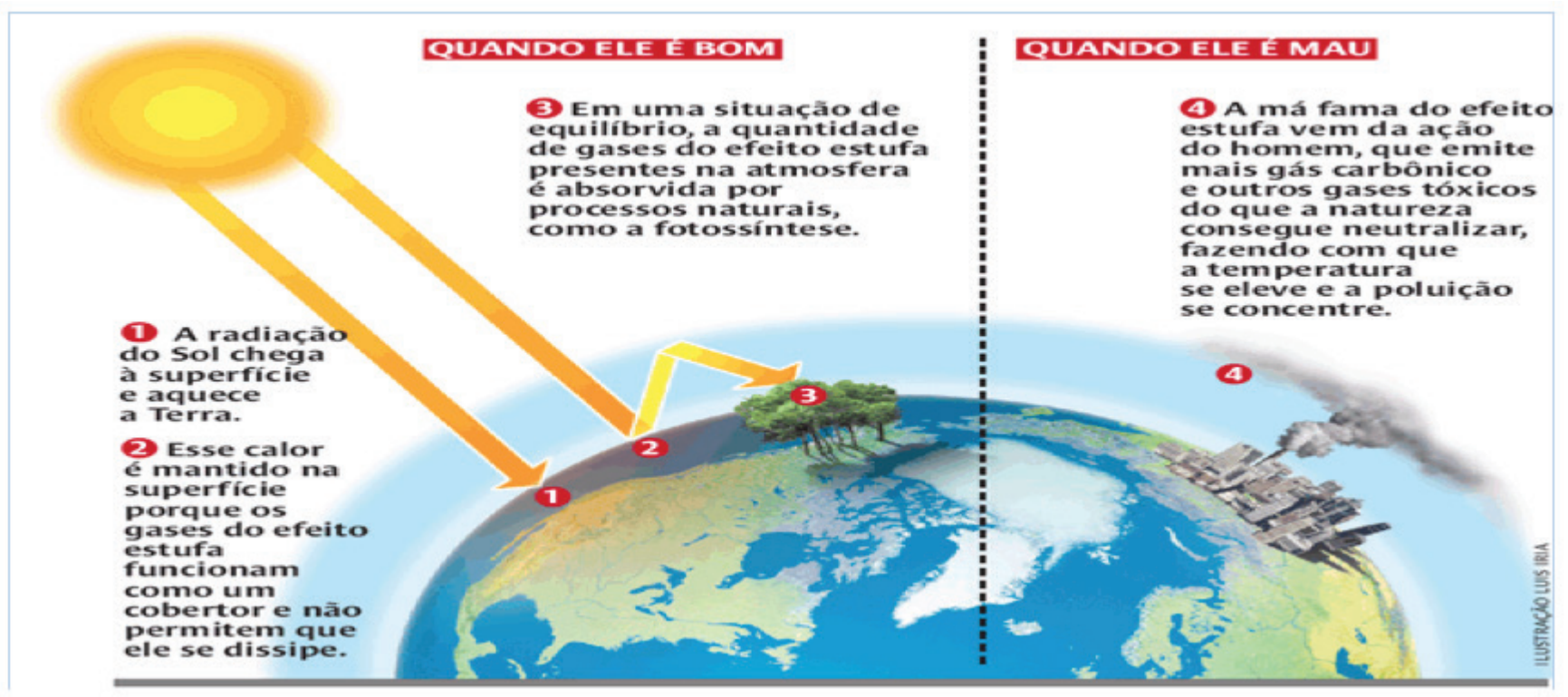

Ilustração: Luis Iria

Os conceitos passados pelas reportagens estão coerentes com os estudos atuais sobre o tema:

O Efeito Estufa é a forma que a Terra tem para manter sua temperatura constante. (...) consiste, basicamente, na ação do dióxido de carbono e outros gases sobre os raios infravermelhos refletidos pela superfície da terra, reenviando-os para ela, mantendo assim uma temperatura estável no planeta. Ao irradiarem a Terra, parte dos raios luminosos oriundos do Sol são absorvidos e transformados em calor, outros são refletidos para o espaço, mas só parte destes chega a deixar a Terra, em consequência da ação refletora que os chamados "Gases de Efeito Estufa" (dióxido de carbono, metano, clorofluorcarboneto s- CFCs- e óxidos de azoto) (...). (ADAMS, 2007. Disponível em: http://www. revistaea.org).

Já o aquecimento global, viria a ser o agravamento do Efeito Estufa. No caso o aquecimento total da Terra, ou seja, todo o planeta, não uma zona específica. Acredita-se que esse aumento na temperatura esteja ocorrendo pela queima de combustíveis fósseis, que permite o acumulo dos gases propícios ao Efeito Estufa (Dióxido de Carbono, o Metano, o Óxido de Azoto e os CFCs) na atmosfera.

Como cada uma das perguntas não questionou a relação do efeito estufa e do aquecimento global, fica um pouco confusa a relação entre os dois; se a primeira pergunta for lida separadamente tem-se a impressão de que o aquecimento global está desvinculado da ação do homem. Apenas quando o segundo questionamento é lido, é que fica claro que o efeito estufa é um fenômeno natural e benéfico para terra, a sua intensificação devido a ação do homem é que contribui para o aquecimento global.

Outro ponto que é bem interessante ser apresentado é o fato de certos questionamentos em relação ao aquecimento global serem omitidos em sala de aula. O aquecimento global sempre causou muitas discussões no meio cientifico, não havendo unanimidade das compreensão conceitual por parte da comunidade cientifica em função do entendimento que se tem das causas, motivos e efeitos. 
Uma das grandes questões científicas atuais é separar o que é do quadro natural da variabilidade do clima e o que é resultante da interferência humana. Então, a pergunta é a seguinte: até que ponto a ação humana está influenciando essas mudanças em um grau além do que é esperado? (Disponível em: http://www.mudancasclimaticas.andi.org.br).

Cada vez mais surgem questionamentos, teorias alarmantes e preocupações sobre a preservação do meio ambiente, porém quando se pensa neste tema, o senso comum o designa só ao verde, florestas, natureza. O meio ambiente é tudo que nos cerca, é onde se vive, come, e mora, logo a crise dita ambiental torna-se socioambiental. É fundamental a compreensão e reflexão de como é concebida a natureza em nossa sociedade (Gonçalves, 2006).

Infelizmente foram poucas as matérias encontradas que abordavam uma concepção e quase nulo o aprofundamento nesse tipo de concepção. O que é possível identificar são soluções bem sucedidas em contextos isolados, baseadas em incentivo a mudança de comportamento e conscientização dos alunos (por exemplo, não jogar lixo no chão, mutirão para limpar a lagoa). Falta certo questionamento, sobre o porquê de tudo isso. Conceitos que vem da filosofia e da definição e construção da sociedade moderno-colonial entram em cena.

Analisando a concepção de Gonçalves (2004, p. 38-39), entendemos como a dominação da natureza dentro dessa sociedade tornou-se natural:

Para dominar a natureza, como manda os fundamentos da sociedade moderno-colonial, é preciso que se dominem os homens, sem o que a natureza não pode ser dominada. (...) é preciso que haja um conjunto de técnicas que faça com que cada um aceite a ideia com natural (...).

O entendimento da dualidade criada para homem-natureza é crucial para o entendimento da crise socioambiental; socioambiental por que esta passa a ser uma crise da sociedade e não da natureza por si só. O homem faz parte da natureza, ele esta nela, ele vive nela.

(...) dominar a natureza só tem sentido a partir da premissa de que o homem é não-natureza... Mas se o homem é também natureza, como falar em dominar a natureza? Teríamos que falar em dominar o homem também...E aqui a contradição fica evidente. Afinal, quem dominaria o homem?" (Gonçalves, 2006. p. 27).

O trabalho do educador dentro de sala de aula deve-se voltar para o reconhecimento do aluno como individuo atuante na sociedade, como o sujeito, mas não como o homem-sujeito que domina a natureza-objeto, este se reconhece no espaço em que está inserido tornando-se assim, responsável por ações e medidas que ocorrem nela, o sujeito pode ser o que age ou o que submete (Gonçalves, 2006). A Geografia é, neste contexto, uma ciência essencial para que o professor torne esta compreensão possível.

\section{REFLEXÕES FINAIS}

Ao longo do trabalho observamos tendências e conceitos geográficos presentes na Revista Nova Escola. Encontramos uma tendência muito frequente: as reportagens com foco de Geografia Física, e Geografia Física e Humana. Também tivemos baixa frequência da Geografia unicamente Humana, da relação desta ciência com outras disciplinas a partir de diferentes temas, ou seja, com enfoque interdisciplinar. 
É inegável a abrangência e influência da Revista Nova Escola dentro do meio escolar, por estar presente em todas as escolas públicas brasileiras. Essa abrangência em si pode gerar certos conflitos, visto que muitas experiências e propostas expostas, só funcionariam em certos contextos isolados. A pluralidade do público que a recebe exige um pouco mais de cuidado quanto às metodologias e sugestões sugeridas.

A quase ausência de material voltado para a Educação Infantil na área geográfica também é um fator muito relevante, visto a importância de certos conceitos que podem e precisam ser inseridos nessa idade escolar, e a importante necessidade de interação com o mundo ao redor desses educandos. O Ensino Fundamental I também não recebe a atenção que deveria, visto o número reduzido de conteúdo voltado para este.

Não se nega o número de conteúdos de todas as áreas do ensino, este é considerável; porém os conteúdos geográficos aparecem pouco, e quando aparecem geralmente são voltados para cartografia de forma desvinculada de outros conteúdos. E mais uma vez, há a defasagem de certos conteúdos voltados para essa fase do ensino, conteúdos que só encontramos no Fundamental II, mas que, poderiam ser trabalhados antes, como o trabalho com conceito de paisagem, cidade, campo, natureza e sociedade.

Relacionar a Geografia ao meio físico e a elementos humanos é uma característica bem forte na revista no que se refere aos títulos e inícios de reportagens dos exemplares de 2000 a 2011. Fica evidente que há o foco em mostrar da melhor forma, por meio das experiências relatadas, que a geografia faz parte das práticas diárias e que esta é necessária para o entendimento do meio. O ensino no Brasil é plural, diverso e atende a um público cheio de especificidades. Adaptar, expor, criar propostas é necessário pra suprir as demandas desse público.

\section{BIBLIOGRAFIA}

Adams, B. (2012). Efeito Estufa e Aquecimento Global - dois conceitos distintos. Mas, qual é a diferença? Publicado em 02/09/2007. Disponível em: http://www.revistaea.org/artigo.php?idartigo $=498 \&$ class $=07$. Acesso em 15 Jan.

Callai, H. (2005). Aprender a ler o mundo: a Geografia nos anos iniciais do Ensino Fundamental. Cadernos Cedes, Campinas, v. 25, n. 66, p.227-247, maio/ago.

Castellar, S. \& M. J.V. (2010). Ensino de Geografia. Coleção Ideias em Ação. Ana Maria de Carvalho (coordenadora). CENGANGE Learning, São Paulo.

Castellar, S. M. V. (2010). Didática da Geografia: aprendizagem significativa. Tese de Livre- Docência. Faculdade de Educação- USP.

Castellar, S. M. V. (2000). Alfabetização em Geografia. Espaços da Escola, Ijuí, v. 10, n. 37, p. 2946, jul./set.

Castellar, S. M. V. (2006). A cidade e a cultura urbana na geografia escolar. Boletim Paulista de Geografia, São Paulo, n. 85, p. 95-111, dez. 
Cavalcanti, L. S. (1998). Geografia, escola e construção de conhecimento. São Paulo: Papirus.

Gonçalves, C. (2004). O desafio ambiental. Os Porquês da Desordem Mundial - Mestres Explicam a Globalização. Org. Emir Sader - Rio de Janeiro: Record.

Gonçalves, C. (2006). Os (des)caminhos do meio ambiente. 14º Edição - São Paulo: Contexto.

Lopes, A. (2008). Políticas de integração curricular. Rio de Janeiro: Eduerj.

Moraes, J.V. de. (2010). A alfabetização científica, a resolução de problemas e a cidadania: uma proposta para o ensino de Geografia. Tese de Doutoramento. Faculdade de Educação- USP.

Straforini, R. (2008). Ensinar Geografia - o desafio da totalidade-mundo nas séries iniciais. 2 ed. São Paulo: Annablume.

Valcárcel, J. O. (2000). Los horizontes de la geografía. 1 ed. Barcelona: Ariel.

\section{Sites consultados:}

Mudanças Climáticas. Críticas e Contra Pontos. Visões Discrepantes. Evidências e Divergências. Publicado em: http://www.mudancasclimaticas.andi.org.br/node/715. Acesso em 15 Jan. 2012.

Revista Nova Escola 2006 à 2011. Disponível em: http://revistaescola.abril.com.br/edicoes-impressas/. Acesso: Ago. 2011 á Jan. 2012.

Revista Nova Escola 2006 à 2011. Disponível em: http://revistaescola.abril.com.br/avulsas/assina-secretarias.shtml. Acesso em 11 Abr. 2012

http://www.grupoabril.com.br/institucional/perfil.shtml. Acesso em 11 Abr. 2012 